\title{
DEVELOPMENT, FORMULATION
} DISSOLVING TABLETS

AND EVALUATION

OF

MECLOFENAMATE FAST

Mahipal Shakkarwal $^{1 *}$, Dr. Mukesh Sharma ${ }^{2}$, Dr. Ram Garg ${ }^{2}$, Shankar Lal Soni ${ }^{2}$, Gopal Kumar Paswan $^{1}$, Umansh Naryan ${ }^{1}$

${ }^{1}$ Research Scholar, Arya College of Pharmacy

${ }^{2}$ Arya college of Pharmacy

Article Info: Received 15 January 2021; Accepted 17 February 2021

DOI: https://doi.org/10.32553/jbpr.v10i1.838

Corresponding author: Mahipal Shakkarwal

Conflict of interest statement: No conflict of interest

\begin{abstract}
The demands for fast dissolving tablets have received ever increasing day by day during the last 10-15 years for the onset of action. In the present study, the effect of superdisintegrant was compared with synthetic super disintegrants and other conventional super disintegrants in the of fast dissolving tablet formulation of Meclofenamate.

Meclofenamate is an antihypertensive drug and in case of hypertension immediate treatment is required so the proposed investigation is totally based to provide the suitable treatment for hypertension.

In the present work 9 formulations of Fast dissolving tablets of Cilnidipine were prepared by using Synthesized Co-proceed was evaluated and compiles with the official standards, parameters and specifications. Various formulations were prepared using four different superdisintegrant namely- kyron T-304, sodium starch glycolate, cross carmelose sodium with three concentrations $(2 \%, 4 \%, 6 \%)$ by direct compression method.

The blend was evaluated for pre-compression parameters like Angle of repose, bulk density, tapped density, and then tablet evaluated post-compression parameters like thickness, drug content, hardness, weight variation, wetting time, friability, disintegration time, dissolution time, drug release study.

Formulation A8 showed the lowest disintegration time and in-vitro dissolution studies recorded that formulation A8 showed $98.64 \%$ drug release at the end of 3 minutes.

The best formulations were also found to be stable and optimized formulations were subjected to the stability studies as per ICH guideline and standards.
\end{abstract}

Keywords:-

Fast dissolving tablet, Meclofenamate, Co-proceed, sodium starch glycolate, Kyron T-314, direct compression, dissolution time.

\section{Introduction}

The tablet is most widely used dosage for because of its convenience in term of self-administration, compactness, accurate dosage and ease in manufacturing. Over this one drawback of conventional tablet is difficulty in swallowing by pediatric and geriatric patients. ${ }^{1}$

To beat these issues the scientists have developed novel drug delivery system that known as fast dissolving tablet. The fast dissolving tablets that dissolving in few seconds in the mouth when they come with contact saline without requirement of additional water. The advantage of FDT (Fast dissolving tablet) is onset of action, higher patient acceptance, and increased bioavailability. ${ }^{2-4}$

Meclofenamate Sodium is the sodium salt form of meclofenamate, an anthranilic acid and nonsteroidal anti-inflammatory drug (NSAID) with anti-inflammatory, antipyretic and analgesic activities. Meclofenamate sodium inhibits the activity of the enzymes cyclo-oxygenase I and II, resulting in decreased formation of precursors of prostaglandins and thromboxanes.

Drug delivery via the oral mucosa is a promising route, when one wishes to achieve a rapid onset of action or improved bioavailability for drugs with high first-pass metabolism. Thus, there is a growing 
interest in developing alternative dosage forms, i.e. orally fast disintegrating strip, which allow a rapidly dissolving drug to absorb directly into the systemic circulation through the oral mucosa

These kinds of dosage forms are also convenient for children, elderly patients with swallowing difficulties, and in the absence of potable liquids. However, in addition to formulation considerations, the properties of the active compound have to be appropriate in order to achieve drug delivery into systemic circulation after intraoral administration.

\section{Material and Method}

Meclofenamate was received as gift sample by Pro Lab Marketing, Mumbai, Magnesium stearate used were procured from Reckon animal health care, Jaipur, Lactose used was procured from Rescue laboratories, Jaipur, Kyron T-314 was gifted by Corel PharmaChem, Ahmadabad,

\section{Pre-Formulation Studies:-}

\section{Angle of Repose ( $\theta)$ :}

Angle of repose is defined as, the maximum possible angle between the surface of the pile of the powder and the horizontal plane of the powder. When more quantity powder is added to the pile, it slides down, until the mutual friction of the particles producing a surface angle $\theta$, is equilibrium with the gravitational force. ${ }^{15-17}$

The angle of repose was determined by the funnel method suggested by the scientist Newman. Angle of repose is determined by the following formula

$$
\text { Tan } \begin{aligned}
\theta & =\mathrm{h} / \mathrm{r} \\
\theta & =\operatorname{Tan}^{-1} \mathrm{~h} / \mathrm{r}
\end{aligned}
$$

Where $\theta=$ Angle of repose

$\mathrm{r}=$ Radius of the cone

$\mathrm{h}=$ height of the cone

\section{Bulk Density:}

Density defined as weight per unit volume. Bulk density is defined as the mass of the powder is divided by the bulk volume of powder and is expressed as $\mathrm{gm} / \mathrm{cm}^{3}$. The bulk density of a powder primarily depends on its, particle shape, particle size, distribution and the tendency of particles to adhere together. There are two types of bulk density. ${ }^{18-21}$

\section{Low Bulk Density}

The particles are pack in such a way so as to leave large gaps between their surfaces resulting up in light powder of low bulk density.

\section{High Bulk Density}

Here the smaller particles shift between the large particles resulting in heavy powder of high bulk density

\section{Tapped Density (DT):}

It was the ratio index of total mass of the powder to tapped volume of the powder. Volume was reported by tapping the powder for 500 times and the tapped volume was recorded, if the difference between these two volumes was less than $2 \%$. If it more than $2 \%$, then tapping was continued for 750 times and tapped volume was noted. Tapping was continued until the difference between volumes was less than $2 \%$ in bulk density apparatus. It was expressed in $\mathrm{g} / \mathrm{ml}$ and was given as following,

$\mathrm{DT}=\mathrm{M} / \mathrm{Vt}$

Where, $\mathrm{M}$ is the mass of powder

$\mathrm{Vt}$ is the tapped volume of the powder. ${ }^{22-24}$

Carr's Index (Or) \% Compressibility:

Carr's index indicates powder flow properties. It is expressed by percentage and is given by:

$\mathrm{I}=\mathrm{DT}-\mathrm{Db} / \mathrm{DT} \times 100$

Where, DT denotes the tapped density of the powder

And

$\mathrm{Db}$ is the bulk density of the powder. ${ }^{25-28}$

\section{Hausner Ratio:}

Hausner ratio is an indirect index of ease of powder flow properties. It is calculated by the following formula:

Hausner ratio $=\mathrm{Dt} / \mathrm{Db}$

Where, Dt show the tapped density.

$\mathrm{Db}$ is the bulk density.

Lower hausner ratio $(<1.25)$ indicates better flow properties than higher ones $(>1.25)$

\section{Evaluatation of Tablet:-}

All prepared tablets of Aceclofenac were evaluated for the following parameters as per IP guideline and standards for all the calculations are represented in the table No.3

\section{Weight Variation:-}

Twenty tablets of Aceclofenac formulation were selected randomly from each of the formulation and weighted individually using Citizen Digital Balance for their weight data. The average weight of the tablets as well as percentage deviation was calculated. ${ }^{29-31}$ 


\section{Hardness:-}

Hardness of the Aceclofenac HCL tablet was measured with the tablet hardness testing apparatus known as Monsanto tablet harness tester. ${ }^{32}$

\section{Thickness:-}

The thickness of the tablet was measured in mm by the Vernier Calipers for all the designed formulation batches.

\section{Friability:-}

The friability of the Aceclofenac HCL tablet, a sample of twenty tablets was measured using USP type Roche Friabilator. The tablets were dusted reweighed and percentage weight-loss was calculated.

$\%$ Friability $=$ Initial Weight - Final Weight $* 100 /$ Initial Weight

\section{Water Absorption Ratio:}

A piece of tissue paper $(12 \mathrm{~cm} \mathrm{X} 10.75 \mathrm{~cm})$ folded twice was placed in small Petri-plate $(\mathrm{ID}=6.5 \mathrm{~cm})$ containing $10 \mathrm{ml}$ of water. A tablet was placed on the paper and time for complete wetting of the tablet was measured in seconds. Three trials for each batch were performed and the standard deviation was also determined. The wetted tablet was weighed and water absorption ratio $\mathrm{R}$, was determined by following equation

$\mathbf{R}=\{(\mathbf{W a}-\mathbf{W b}) / \mathbf{W a}\} \times \mathbf{1 0 0}$

Where, Wa and $\mathrm{W}_{\mathrm{b}}$ were weights of the tablets after and before study. ${ }^{33-35}$

\section{Wetting Time}

A piece of tissue paper $(12 \mathrm{cmX} 10.75 \mathrm{~cm})$ folded twice was placed in a small Petri dish (ID $=9 \mathrm{~cm}$ ) containing $6 \mathrm{ml} \mathrm{pH} 6.8$ phosphate buffer, A tablet was placed on the paper and the time taken for complete wetting was noted. Three tablets from each formulation were randomly selected and the average wetting time was noted.

\section{Disintegration Study:-}

Disintegration time study was carried out by selecting 6 tablets of Aceclofenac and performed disintegration test (Lab India) using $900 \mathrm{ml}$ distilled water at temperature $\left(37^{0} \mathrm{C} \pm 2^{0} \mathrm{C}\right){ }^{36}$

\section{Dissolution Study:-}

The In-vitro for the dissolution study was carried out in the USP (United state pharmacopeia) dissolution test apparatus type 2 known as Paddle dissolution apparatus, used phosphate buffer as dissolution medium as $900 \mathrm{ml}$ containing $\mathrm{PH} 6.8$ was taken in vessel and the temperature maintained at $37 \pm 0.5^{\circ} \mathrm{C}$. The speed of the paddle was set at RPM 50, then $5 \mathrm{ml}$ dissolution medium was withdrawn and the same amount $(5 \mathrm{ml})$ of fresh medium was replenished to the dissolution medium. The calculations of the Concentration were calculated by absorbance base. The release of the drug was performed in replicates of three. ${ }^{37-38}$

\section{Preparation of Fast Dissolving Tablet of Meclofenamate}

The critical parameters to formulate fast dissolving tablet are choice of super disintegrants and optimization of concentration of superdisintegrants. The main criteria for fast dissolving tablets is to disintegrate or dissolve rapidly in oral cavity in 1560 seconds, without need of water and should have pleasant mouth feel. The Fast dissolving tablet of Meclofenamate are prepared by using direct compression method with the incorporation of superdisintegrants like Microcrystalline cellulose (MCC), Sodium starch glycolate, Croscarmellose Sodium (CCS), with Meclofenamate equivalent to 8 mg, Mannitol and Microcrystalline Cellulose are mixed thoroughly in glass mortar using a pestle. Superdisintegrants were incorporated in the powder mixture according to each formulation in the tablets and finally Aspartame, and Magnesium stearate and flavour was added. The whole mixture was passed through Sieve No. 60 twice. Tablets were prepared by using Shakti Pharmatech 10 station punching machine. The compression force was constant during Punch.

Table 1: Meclofenamate Fast Dissolving Tablets by Direct Compression Method

\begin{tabular}{|l|c|c|c|c|c|c|c|c|c|}
\hline Ingredients (mg) & F1 & F2 & F3 & F4 & F5 & F6 & F7 & F8 & F9 \\
\hline Meclofenamate & 100 & 100 & 100 & 100 & 100 & 100 & 100 & 100 & 100 \\
\hline Crosscarmellose Sodium & 3 & 6 & 9 & - & - & - & - & - & - \\
\hline Sodium Starch Glycolate & - & - & - & 3 & 6 & 9 & - & - & - \\
\hline Crosspovidone & - & - & - & - & - & - & 3 & 6 & 9 \\
\hline Aspartame & 1.5 & 1.5 & 1.5 & 1.5 & 1.5 & 1.5 & 1.5 & 1.5 & 1.5 \\
\hline Flavour & 1.5 & 1.5 & 1.5 & 1.5 & 1.5 & 1.5 & 1.5 & 1.5 & 1.5 \\
\hline
\end{tabular}




\begin{tabular}{|l|c|c|c|c|c|c|c|c|c|}
\hline Talc & 1.5 & 1.5 & 1.5 & 1.5 & 1.5 & 1.5 & 1.5 & 1.5 & 1.5 \\
\hline Magnesium Stearate & 1.5 & 1.5 & 1.5 & 1.5 & 1.5 & 1.5 & 1.5 & 1.5 & 1.5 \\
\hline Mannitol & 20 & 17 & 14 & 20 & 17 & 14 & 20 & 17 & 14 \\
\hline Lactose & 21 & 21 & 21 & 21 & 21 & 21 & 21 & 21 & 21 \\
\hline TOTAL & $\mathbf{1 5 0}$ & $\mathbf{1 5 0}$ & $\mathbf{1 5 0}$ & $\mathbf{1 5 0}$ & $\mathbf{1 5 0}$ & $\mathbf{1 5 0}$ & $\mathbf{1 5 0}$ & $\mathbf{1 5 0}$ & $\mathbf{1 5 0}$ \\
\hline
\end{tabular}

\section{Result and Discussion}

\section{Analytical Profile of Meclofenamate:}

The DSC thermogram of Meclofenamate is shown in Figure 1. The DSC thermogram of Meclofenamate showed sharp peak at $279^{\circ} \mathrm{C}$. The identity of a compound was confirmed by comparison with that of an authentic sample and verification of the presence of functional groups in an unknown molecule was done by IR spectra. The IR spectra obtained was elucidated for important chromophore groups. The IR spectra showed peaks at 3311, 2924, 2854, 1651,1511, 1163 and $551 \mathrm{~cm}^{-1}$. The various peaks are depicted below.

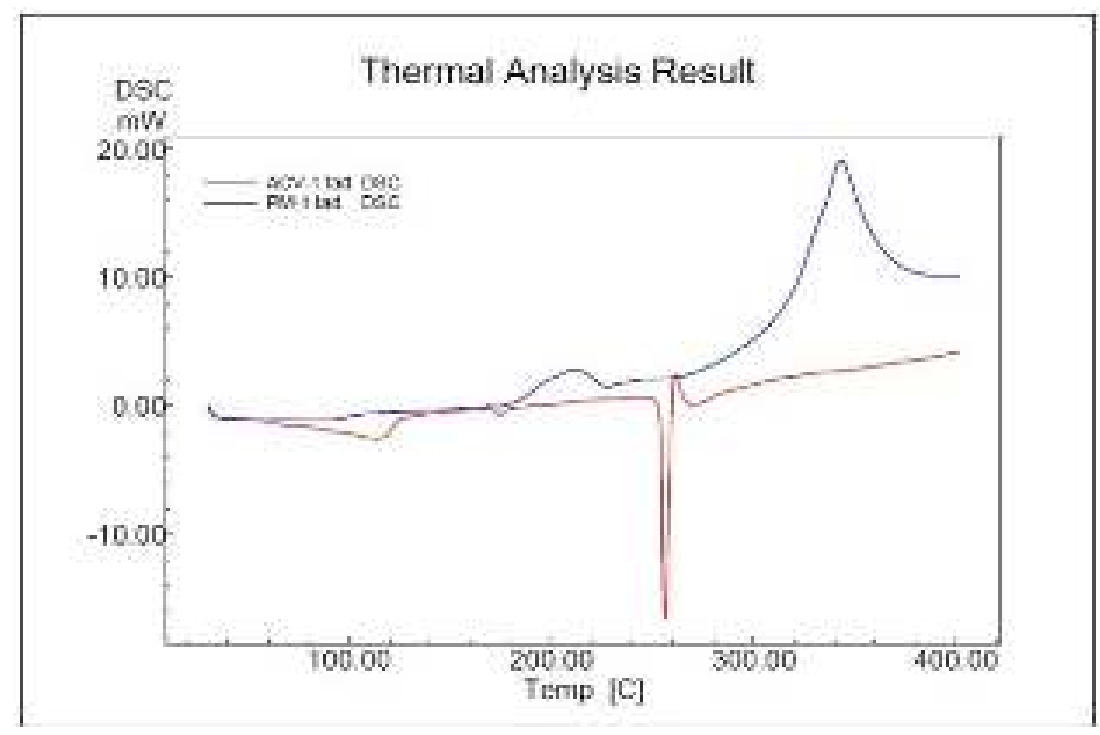

Figure 1: DSC Thermogram of Meclofenamate

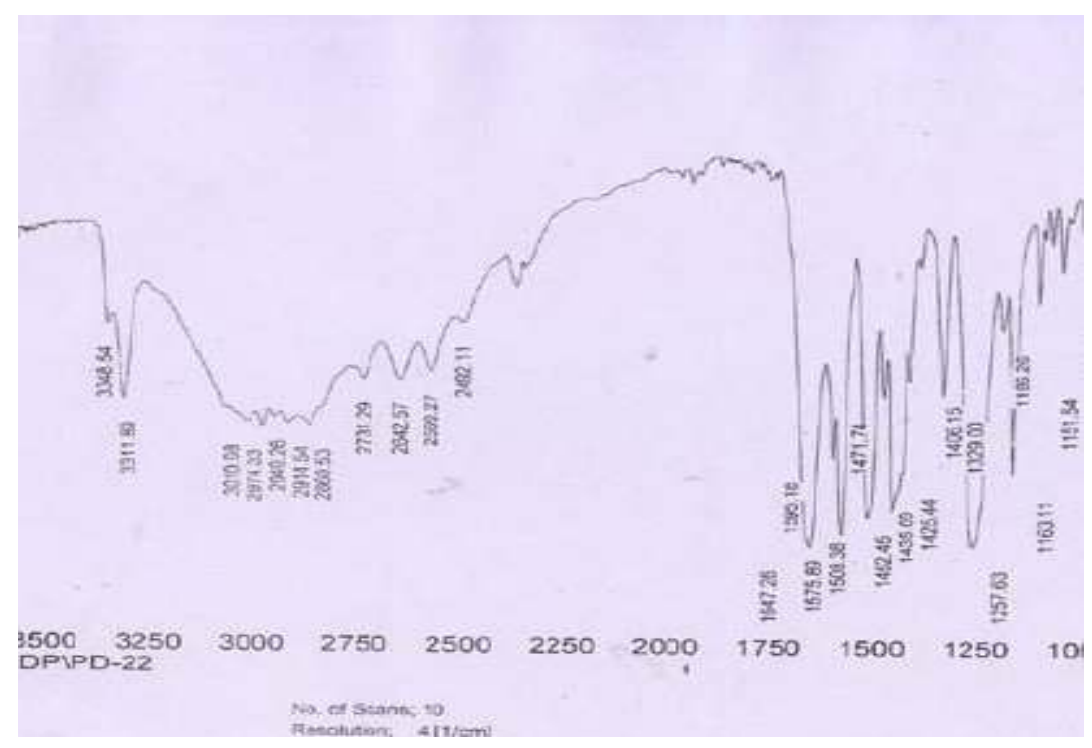

Figure 2: IR Spectra of Meclofenamate 
Table 2: Determination of maxima wavelength $\left(\lambda_{\max }\right)$

\begin{tabular}{|c|c|}
\hline Wavelength (nm) & Absorbance \\
\hline 320 & 0.998 \\
\hline 290 & 0.558 \\
\hline 268 & 0.359 \\
\hline 285 & 0.757 \\
\hline 240 & 0.192 \\
\hline 350 & 1.075 \\
\hline
\end{tabular}

The calibration curve of Meclofenamate was prepared in Phosphate Buffer $\mathrm{pH} 7.4$ at $320 \mathrm{~nm}$ and the absorbance values of different concentrations of Meclofenamate solutions in Phosphate Buffer pH 7.4

Table 3: Calibration Curve Data of Meclofenamate

\begin{tabular}{|c|c|}
\hline Concentration & Absorbance (320 nm) \\
\hline 0.0 & 0 \\
\hline 2.0 & 0.173 \\
\hline 4.0 & 0.321 \\
\hline 6.0 & 0.472 \\
\hline 8.0 & 0.621 \\
\hline 10.0 & 0.752 \\
\hline 12.0 & 0.851 \\
\hline
\end{tabular}

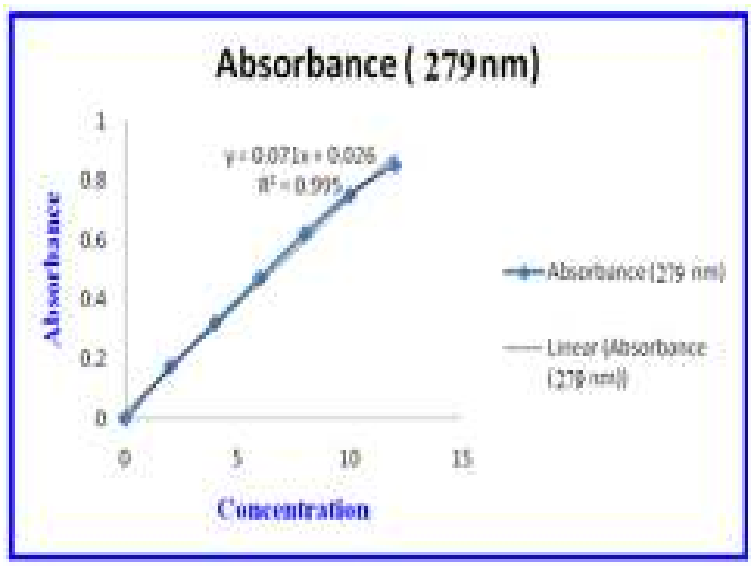

Figure 3: Calibration Curve of Meclofenamat

Solubility of Meclofenamate was determined in different solvents and the observations are shown in Table 5. The maximum solubility was found in DMSO and least in water. Partition coefficient of Meclofenamate in Phosphate buffer $\mathrm{pH} 7.4$ was found to be 3

Table 4: Characterization of blends

\begin{tabular}{|l|l|l|l|l|l|}
\hline Parameters & $\begin{array}{l}\text { Bulk Density } \\
(\mathbf{m g} / \mathbf{m l})\end{array}$ & $\begin{array}{l}\text { Tapped Density } \\
(\mathbf{m g} / \mathbf{m l})\end{array}$ & Hausners Ratio & $\begin{array}{l}\text { Compressibilty Index } \\
(\mathbf{\%})\end{array}$ & $\begin{array}{l}\text { Angle of Repose } \\
(\mathbf{0})\end{array}$ \\
\hline Formulation & 0.597 & 0.627 & 1.185 & 14.25 & 24.19 \\
\hline $\mathbf{F}_{\mathbf{1}}$ & 0.528 & 0.616 & 1.109 & 15.89 & 25.32 \\
\hline $\mathbf{F}_{\mathbf{2}}$ & 0.535 & 0.495 & 1.115 & 16.28 & 24.45 \\
\hline $\mathbf{F}_{\mathbf{3}}$ & 0.554 & 0.642 & 1.171 & 14.87 & 24.52 \\
\hline $\mathbf{F}_{\mathbf{4}}$ & 0.542 & 0.592 & 1.169 & 15.98 & 25.11 \\
\hline $\mathbf{F}_{\mathbf{5}}$ & 0.551 & 0.692 & 1.178 & 16.89 & 24.19 \\
\hline $\mathbf{F}_{\mathbf{6}}$ & 0.509 & 0.551 & 1.171 & 15.05 & 25.29 \\
\hline $\mathbf{F}_{\mathbf{7}}$ & 0.501 & 0.561 & 1.172 & 15.10 & 25.20 \\
\hline $\mathbf{F}_{\mathbf{8}}$ & 0.508 & 0.592 & 1.164 & 14.20 & 25.32 \\
\hline $\mathbf{F}_{\mathbf{9}}$ & & & & \\
\hline
\end{tabular}




\section{Characterization of Fast Dissolving Tablets of Meclofenamate}

On the characterization of the drug free tablet the best formulations were selected and the drug Meclofenamate was incorporated in these formulation. The characterization of mixed blend done for the flow property of powder that are bulk density, tapped density, angle of repose, Compressibility index, Hausner's ratio were shown in Table 5.

Table 5: Pre-compression Characterization of blend of Meclofenamate tablet

\begin{tabular}{|c|c|c|c|c|c|}
\hline $\begin{array}{c}\text { Parameter } \\
\mathbf{S}\end{array}$ & $\begin{array}{c}\text { Bulk } \\
\text { Density }\end{array}$ & $\begin{array}{c}\text { Tapped } \\
\text { Density }\end{array}$ & \multirow{2}{*}{$\begin{array}{c}\text { Hausners } \\
\text { Ratio }\end{array}$} & $\begin{array}{c}\text { Compressibilty } \\
\text { Index }\end{array}$ & $\begin{array}{c}\text { Angle of } \\
\text { Repose }\end{array}$ \\
\cline { 1 - 2 } \cline { 5 - 6 } Formulatin & $\mathbf{( m g} / \mathbf{m l})$ & $\mathbf{( m g / m l )}$ & & $\mathbf{( \% )}$ & $\mathbf{0}$ \\
\hline $\mathbf{F}_{\mathbf{1}}$ & $0.591 \pm 0.12$ & $0.621 \pm 0.11$ & $1.180 \pm 0.05$ & $14.25 \pm 0.15$ & $24.19 \pm 1.38$ \\
\hline $\mathbf{F}_{\mathbf{2}}$ & $0.521 \pm 0.11$ & $0.616 \pm 0.69$ & $1.100 \pm 0.09$ & $15.89 \pm 0.23$ & $25.32 \pm 1.35$ \\
\hline $\mathbf{F}_{\mathbf{3}}$ & $0.531 \pm 0.18$ & $0.495 \pm 0.54$ & $1.101 \pm 0.19$ & $16.28 \pm 0.28$ & $24.45 \pm 1.40$ \\
\hline $\mathbf{F}_{\mathbf{4}}$ & $0.551 \pm 0.17$ & $0.642 \pm 0.22$ & $1.171 \pm 0.15$ & $14.87 \pm 0.55$ & $24.52 \pm 0.55$ \\
\hline $\mathbf{F}_{\mathbf{5}}$ & $0.540 \pm 0.05$ & $0.592 \pm 0.29$ & $1.161 \pm 0.19$ & $15.98 \pm 0.63$ & $25.11 \pm 1.25$ \\
\hline $\mathbf{F}_{\mathbf{6}}$ & $0.551 \pm 0.11$ & $0.692 \pm 0.27$ & $1.175 \pm 0.58$ & $16.89 \pm 0.89$ & $24.19 \pm 1.89$ \\
\hline $\mathbf{F}_{\mathbf{7}}$ & $0.501 \pm 0.15$ & $0.551 \pm 0.10$ & $1.170 \pm 1.01$ & $15.05 \pm 0.25$ & $25.29 \pm 0.15$ \\
\hline $\mathbf{F}_{\mathbf{8}}$ & $0.500 \pm 0.01$ & $0.561 \pm 0.19$ & $1.171 \pm 1.12$ & $15.10 \pm 0.55$ & $25.20 \pm 0.29$ \\
\hline $\mathbf{F}_{\mathbf{9}}$ & $0.502 \pm 0.12$ & $0.591 \pm 0.11$ & $1.161 \pm 1.14$ & $14.20 \pm 0.56$ & $25.32 \pm 1.11$ \\
\hline
\end{tabular}

The prepared drug tablets were evaluated as similar as the drug free tablets. After compression of powder the tablet were evaluated for physical organoleptic characteristics like colour, odour, taste, diameter, Thickness, Hardness, Friability, dispersion time, Disintegration time, wetting time.

All the formulations were exhibit in white colour, odorless, convex in shape with smooth surface with zero defects. The average weight of the prepared tablet was found 145.07 to $154.05 \mathrm{mg}$. The thickness of the tablet was found $3 \mathrm{~mm}$. The diameter of the tablets was found to be $4 \mathrm{~mm}$. The hardness of the prepared tablet varied from 3.01 to $3.20 \mathrm{Kg} / \mathrm{cm}^{2}$. Which have satisfactory strength to withstand the mechanical shocks. The friability of all the formulation was found to be less than $1.0 \%$. The results shows resistance to loss of weight indicates the tablet's ability to withstand abrasion in handling, packaging and shipment. The disintegration time of the tablets was varied from 30 to 69 seconds. The in vitro swelling time of all the formulations were varied between 14 to 22 seconds.

Table 6: Characterization of Meclofenamate fast dissolving tablet

\begin{tabular}{|l|c|c|c|c|c|c|c|}
\hline Parameters & Diameter & Thickness & Weight (mg) & Hardness & Friability & Disintegration Time & $\begin{array}{c}\text { Swelling } \\
\text { Time (Sec) }\end{array}$ \\
\cline { 1 - 1 } Formulation & $\mathbf{( m m )}$ & $\mathbf{( m m )}$ & & $\mathbf{( K g / \mathbf { c m } ^ { 2 } )}$ & $\mathbf{( \% )}$ & $\mathbf{( S e c )}$ & $15 \pm 1$ \\
\hline $\mathbf{F}_{\mathbf{1}}$ & 4 & 3 & $154.05 \pm 0.55$ & $3.05 \pm 0.15$ & $0.48 \pm 0.84$ & $44 \pm 1.44$ & $14 \pm 2$ \\
\hline $\mathbf{F}_{\mathbf{2}}$ & 4 & 3 & $145.07 \pm 0.78$ & $3.09 \pm 0.01$ & $0.59 \pm 0.25$ & $39 \pm 1.14$ & $16 \pm 1$ \\
\hline $\mathbf{F}_{\mathbf{3}}$ & 4 & 3 & $147.01 \pm 0.11$ & $3.14 \pm 0.99$ & $0.57 \pm 0.17$ & $45 \pm 1.46$ & $21 \pm 1$ \\
\hline $\mathbf{F}_{\mathbf{4}}$ & 4 & 3 & $152.02 \pm 0.25$ & $3.10 \pm 0.12$ & $0.51 \pm 0.16$ & $63 \pm 1.25$ & $22 \pm 2$ \\
\hline $\mathbf{F}_{\mathbf{5}}$ & 4 & 3 & $154.01 \pm 0.11$ & $3.08 \pm 0.01$ & $0.69 \pm 0.12$ & $69 \pm 1.52$ & $17 \pm 2$ \\
\hline $\mathbf{F}_{\mathbf{6}}$ & 4 & 3 & $152.05 \pm 0.15$ & $3.20 \pm 0.10$ & $0.75 \pm 0.32$ & $49 \pm 1.36$ & $13 \pm 2$ \\
\hline $\mathbf{F}_{\mathbf{7}}$ & 4 & 3 & $150.01 \pm 0.15$ & $3.15 \pm 0.05$ & $0.65 \pm 0.13$ & $31 \pm 1.01$ & $12 \pm 2$ \\
\hline $\mathbf{F}_{\mathbf{8}}$ & 4 & 3 & $150.00 \pm 0.04$ & $3.01 \pm 0.09$ & $0.62 \pm 0.23$ & $30 \pm 1.59$ & $13 \pm 8$ \\
\hline $\mathbf{F}_{\mathbf{9}}$ & 4 & 3 & $147.02 \pm 0.22$ & $3.20 \pm 0.28$ & $0.38 \pm 0.19$ & $33 \pm 1.58$ & 19 \\
\hline
\end{tabular}

The drug content of all the formulations was determined spectrophotometrically at $279 \mathrm{~nm}$. It varied from 139.66 to $147.96 \mathrm{mg}$ per tablet. 
Table 7: Drug Content in the Fast Dissolving Tablet of Meclofenamate

\begin{tabular}{|l|l|l|}
\hline Parameters & Drug Content & \% Drug Content \\
\hline Formulation & (mg per Tablet) & \\
\hline $\mathbf{F}_{\mathbf{1}}$ & $139.66 \pm 0.025$ & 93.11 \\
\hline $\mathbf{F}_{\mathbf{2}}$ & $142.83 \pm 0.041$ & 95.22 \\
\hline $\mathbf{F}_{\mathbf{3}}$ & $140.32 \pm 0.125$ & 93.55 \\
\hline $\mathbf{F}_{\mathbf{4}}$ & $141.33 \pm 0.720$ & 94.22 \\
\hline $\mathbf{F}_{\mathbf{5}}$ & $145.20 \pm 0.385$ & 96.28 \\
\hline $\mathbf{F}_{\mathbf{6}}$ & $141.37 \pm 0.251$ & 94.25 \\
\hline $\mathbf{F}_{\mathbf{7}}$ & $145.33 \pm 0.558$ & 96.89 \\
\hline $\mathbf{F}_{\mathbf{8}}$ & $147.96 \pm 0.385$ & 98.64 \\
\hline $\mathbf{F}_{\mathbf{9}}$ & $146.25 \pm 0.250$ & 97.50 \\
\hline
\end{tabular}

Table 8: Fit of Various Kinetic Models for Fast Dissolving Tablet of Meclofenamate

\begin{tabular}{|l|l|l|l|l|}
\hline Formulation Code & Zero Order $\mathbf{R}^{2}$ & First Order $\mathbf{R}^{\mathbf{2}}$ & Higuchi Model $\mathbf{R}^{\mathbf{2}}$ & ${\text { Korsemeyer Model } \mathbf{R}^{\mathbf{2}}}$ \\
\hline F1 & 0.836 & 0.981 & 0.972 & 0.993 \\
\hline F2 & 0.815 & 0.964 & 0.966 & 0.952 \\
\hline F3 & 0.821 & 0.967 & 0.969 & 0.973 \\
\hline F4 & 0.796 & 0.965 & 0.963 & 0.941 \\
\hline F6 & 0.807 & 0.989 & 0.965 & 0.996 \\
\hline F7 & 0.791 & 0.985 & 0.962 & 0.984 \\
\hline F8 & 0.790 & 0.977 & 0.963 & 0.959 \\
\hline F9 & 0.789 & 0.992 & 0.964 & 0.974 \\
\hline
\end{tabular}

\section{Summary and Conclusion}

It can be concluded from the whole study that fast dissolving tablets of Meclofenamate drug. Coprocced superdisintegrant can be used as pharmaceutical excipients for oral drug delivery. So co-procced superdisintegrant like Kyron T-314 exhibited faster drug dissolution which leads to improve bioavailability, effective therapy (Therapeutic ratio), improve patient compliance, and satisfies all the standards as fast dissolving tablet. It was concluded formulation A8 maximum percentage drug release was found 98.64, with Kyron T-314 with 4\%.

From the study, it was concluded that co-procced superdisintegrant like Kyron T-314 showed better disintegrating property over the synthetic super disintegrate like, SSG(Sodium starch glycolate) CCS (Crosscarmelose Sodium).

\section{Reference:}

1. Sharma ashok kumar, et al., Formulation and evaluation fast dissolving tablet of tizanidine $\mathrm{HCl}$ using fenugreek seed mucilage by direct compression method, IJPSR june 2017, 1(2): $38-42$.

2. Sharma ashok kumar et al., Formulation and evaluation fast dissolving tablet of Domperidone using fenugreek seed mucilage by direct compression method, WJPPS 10.20959/wjpps20177-9580.

3. https://www.rxlist.com/meclofenamatedrug.htm\#clinpharm

4. http://www.enzolifesciences.com/BMLEI163/meclofenamate-sodium.

5. https://pubchem.ncbi.nlm.nih.gov/compound/M eclofenamate-sodium\#section=Structures

6. https://www.webmd.com/drugs/2/drug8673/meclofenamate-oral/details.

7. https://www.drugbank.ca/salts/DBSALT001241 /meclofenamate.

8. https://www.drugs.com/monograph/meclofena mate-sodium.html.

9. https://en.wikipedia.org/wiki/Meclofenamic_aci d.

10. Sharma Ashok, Nareda M. Formulation, Development and In-vitro Evaluation of Fast Dissolving Tablet of Aceclofenac using coprocessed Superdisintegrant by Direct Compression Method. Int. J. Pharm. Sci. Rev. Res., 54(2), January - February 2019; Article No. 12, Pages: 67-72. 
11. Sisodiya, R. (2019). Formulation of fast dissolving ketoprofen tablet by solid dispersion technique. Journal of Drug Delivery and Therapeutics, 8(6-A), 85-92.

12. Dwivedi, A., and G. N. Darwhekar. "Research Paper Design, Optimization And Evaluation Of Empagliflozin Orodispersible Tablets Using Different Superdisintegrants". International Journal of Pharmacy and Pharmaceutical Sciences, Vol. 11, no. 7, May 2019, pp. 32-41.

13. Gunda RK, Manchineni PR, Reddy CG, et al. Formulation development and in vitro evaluation of oral disintegrating tablets for newer anticonvulsant agent. J Anal Pharm Res. 2019;8(2):85-89.

14. Santosh Kumar R, Kumari A, Fast dissolving tablets: waterless patient compliance dosage forms, Journal of Drug Delivery and Therapeutics. 2019; 9(1):303-317.

15. Rahane RD, Rachh PR, A review on fast dissolving tablet, Journal of Drug Delivery and Therapeutics. 2018;8(5):50-55.

16. Rathore, N., Nizami, T., Mangal, A., Malviya, N., Chauhan, V., \& Salvi, N. (2019). Formulation and Evaluation of Fast Dissolving Oral Films of an Anti-Migrain Drug (Zolmitriptan). Journal of Drug Delivery and Therapeutics, 9(2-A), 59-61.

17. Kaur P, Garg R, Oral dissolving film: present and future aspects, Journal of Drug Delivery and Therapeutics. 2018; 8(6):373-377.

18. G, S. "Formulation And Evaluation Of Fast Dissolving Tablet Of Ketorolac Tromethamine Asian Journal of Pharmaceutical and Clinical Research, Vol. 11, no. 16, Dec. 2018, pp. 163169.

19. Romina Sapera, T. N. (2017). Fast Dissolving Oral Film: Challenges and Opportunities for Drug Delivery. International Journal of Information Research and Review, December, 2017, 4836-4840.

20. Nareda M, Sharma A., Design And Formulation Of Fast Dissolving Tablet Of Lornoxicamusing Banana Powder As Natural Superdisintegrant By Direct Compression Method. Wjpps, Vol 7, Issue 2, 2018, Pages: 631-642.

21. Sharma Ashok, Sharma V. Formulation And Evaluation of Fast Dissolving Tablet Of Domperidone Using Fenugreek Seed Mucilage As Natural Superdisintegrant By Direct Compression Method. Wjpps, Vol 7, Issue 2, 2018, Pages: 643-653.
22. Ali MS, Vijendar C, Kumar SD, Krishnaveni J (2016) Formulation and Evaluation of Fast Dissolving Oral Films of Diazepam. J Pharmacovigilance 4: 210

23. Irfan M, Rabel, (2016) Orally disintegrating films: A modern expansion in drug delivery system, Saudi pharmaceutical journal. Volume 24, Issue 5, September 2016, Pages 537-546.

24. M. Vinod Kumar (2016), Formulation and Evaluation of Meclizine Hcl Orally Dispersible Tablets by Using Natural Super Disintegrants. Int J Pharm Sci \& Scient Res.2:1, 53-80.

25. A. Sultan, J.B.Park et al, (2015) Mefenamic acid taste-masked oral disintegrating tablets with enhanced solubility via molecular interaction produced by hot melt extrusion technology, Journal of Drug Delivery Science and Technology, 2015.

26. Damodar R, Movva B, Mallikarjun PN, Pasumarthy C, Kona N, et al. (2014) Formulation and Evaluation of Fast Dissolving Tablets of Diclofenac Sodium by Novel Hole Technology. J Mol Pharm Org Process Res 2:116.

27. Gupta MM, Gupta N, Chauhan BS, Pandey S. Fast Disintegrating Combination Tablet of Taste Masked Levocetrizine Dihydrochloride and Montelukast Sodium: Formulation Design, Development, and Characterization. J Pharm (Cairo). 2014:568320.

28. B. Sujatha,G. R. K. Mohan, M. Krishna Veni ,P. Yanadaiah, B. Suman Kumar.: Effect of superdisintegrants on release of domperidone from fast Dissolving tablets .Journal of Global Trends in Pharmaceutical Sciences 2014,5(3), 1973-1978.

29. Anisree. G. S, Anu. V, Rauof. P , Megha.V, Jouhara. O. P, Abeera. C. H. ;Design and Evaluation of Mouth Dissolving Tablet of Levocetrizine Hydrochloride. Sch. Acad. J. Pharm., 2014, 3(1),45-49.

30. Subbaiah B.V , Krishnamoorthy B, Muthukumaran M.: Formulation and Evaluation of Trihexyphenidyl $\mathrm{HCl}$ Fast Dissolving Tablets . Int J Adv Pharm Gen Res, 2014, 2(2), 1-8.

31. Kishor VS, (2016) orally disintegrating films: A modern expansion in drug delivery system, Saudi pharmaceutical journal. Volume 24, Issue 5, September 2016, Pages 537-546.

32. Baghel P et al, (2013) Fast Dissolving Drug Delivery Systems: A Brief Review, Research J. 
Pharm. and Tech. 6(6): June 2013, Pages 598602.

33. Saroha KamaL, Kumar Gautam , Paul Yash.: Formulation and evaluation of fast dissolving tablets of amoxicillin trihydrate using Synthetic superdisintegrants. Int $\mathrm{J}$ Pharm Bio Sci 2013,4(1),254 - 262.

34. Bhati Savita,Sethi Vandana.: Formulation and evaluation of fast dissolving tablets of metoclopramide hydrochloride using natural sweetening agent of stevia leaf powder. Int. J. Res. Dev. Pharm. L. Sci. 2013,3(1),833-838.

35. Pavan K. Rawat, Prakash B. Mote, Shailendra Singh K., Amarjit A. Salunke, Vivek B. Rajendra,Nityanand S. Zadbuke.: Fast Dissolving Tablets Of Pioglitazone Hydrochloride By Use Of Various Superdisintegrants. IJARPB: 2013, 3(2), 74-79.

36. Rane D.V,Gulve H.N,Patil V.V.: Formulation and evaluation of fast dissolving tablet of albendazole. International Current Pharmaceutical Journal. 2012, 1(10), 311-316.

37. Panigrahi Rajeshree, Chowdary K.A., Mishra Gitanjali, Bhowmik Manas, Behera
Saiprasanna.: Formulation of fast dissolving tablets of Lisinopril using combination of synthetic superdisintegrants. Asian J. Pharm. Tech. 2012,2(3),94-98.

38. Raghavendra Rao N. G., Kumar, Mahesh , Reddy Mettu Srikanth, Kistayya C.Mahipal Reddy B.: Development and Evaluation of Fast Dissolving Tablets of Fosinopril by Sublimation Method International .Journal of Pharmaceutical Sciences and Drug Research 2012, 4(4), 230-235.

39. Kulkarni Upendra , Rao NG. Raghavendra.: Formulation and development of lornoxicam Fast dissolving tablets: influence of different Excipients on property and performance of Patient friendly dosage form. International journal of pharmaceutical and chemical sciences 2012, 1(1),67-74

40. Shah Nihar, Parmar Saurabh, Patel Nisith, Patel K.R.: Formulation and development of fast disintigrating tablets using ranitidine $\mathrm{Hcl}$ as a model drug. JPSBR 2011,1(1),6570. 